ORIGINAL ARTICLE

\title{
Effects of coastal orientation and depth on the distribution of subtidal benthic assemblages
}

\author{
Gustavo M. Martins ${ }^{1,2}$, Rita F. Patarra ${ }^{1,2}$, Nuno V. Álvaro ${ }^{1,2}$, Afonso C. L. Prestes ${ }^{1,2}$ \& Ana I. Neto ${ }^{1,2}$ \\ 1 CIIMAR - Centro Interdisciplinar de Investigação Marinha e Ambiental, Porto, Portugal \\ 2 CIRN and Grupo de Biologia Marinha, Universidade dos Açores, Ponta Delgada, Azores, Portugal
}

\begin{abstract}
Keywords
Abiotic processes; community structure; invertebrates; macroalgae; spatial scales.

\section{Correspondence}

Gustavo M. Martins, CIRN and Grupo de Biologia Marinha, Universidade dos Açores, 9501-801 Ponta Delgada, Azores, Portugal. E-mail: gmartins@uac.pt
\end{abstract}

Accepted: 30 September 2012

doi: 10.1111/maec. 12014

\begin{abstract}
A better understanding of biological systems can only be gained if we understand what processes are important and how they operate to determine the distribution of organisms. Coastal orientation and depth can influence environmental conditions, including the degree of water motion and availability of light, which in turn may influence the horizontal and vertical patterns of organism distribution. Here, we used a mixed-model design to examine the effects of coastal orientation and depth on the structure of benthic assemblages by comparing the abundance and distribution of macroalgae and invertebrates in shallow and deep waters on the opposing coasts of São Miguel. Generally, coastal orientation had little influence on the distribution of most taxa. In contrast, significant differences were generally associated with depth, although patterns were spatially variable at the scale of locations. This study suggests that depth, and processes operating at the scale of location, but not at the scale of the coast, have an important influence on these assemblages, and that failure to recognise such a scale of variability may hamper our ability to better understand the processes that structure these communities.
\end{abstract}

\section{Introduction}

Spatial (or temporal) patterns of organism distribution are naturally heterogeneous (e.g. Underwood 1981; Underwood \& Chapman 1996; Menconi et al. 1999) and are the result of complex interactions between biological and environmental processes (e.g. Lubchenco \& Menge 1978; Benedetti-Cecchi et al. 2000; Jonsson et al. 2006). Understanding how different processes interact and influence the structure of assemblages is thus a fundamental goal of ecology with both a theoretical and applied interest.

Coastal orientation can determine a number of environmental conditions, which in turn may influence the distribution of organisms. For instance, coastal orientation can determine the degree of exposure to predominant winds and oceanic swells (e.g. leeward versus windward coasts of islands). Wave-action has profound effects on nearly all aspects of an organism's life (Denny 1988), such as recruitment and dislodgment of organisms (e.g. Vadas et al. 1990; Blanchette 1997), supply of food and nutrients (e.g. McQuaid \& Lindsay 2007) and foraging activities of consumers (e.g. Vergés et al. 2009; Taylor \& Schiel 2010). A well known example is that presented by Lubchenco \& Menge (1978) from along the coast of New England, where wave-action indirectly determines mussel dominance by directly regulating the abundance of its main predators (star-fish and whelks). It is thus not surprising that differences in community structure have been found between the leeward and windward coasts of islands (e.g. Hassett \& Boehlert 1999; Tuya \& Haroun 2006; Wernberg \& Connell 2008).

Differences in community structure between coasts exposed to similar conditions of wave exposure can also arise due to differences in patterns of oceanographic conditions between coasts. For instance, Menge et al. (1999, 2003) showed consistent differences in community structure between coasts in New Zealand and attributed these to differences in species interactions as mediated by the influence of oceanographic conditions (e.g. formation of eddies, upwelling). 
Another key factor in subtidal marine ecosystems is depth, which influences the vertical distribution of a number of environmental conditions. For instance, light intensity and water motion decline with increasing depth, affecting the photosynthetic rate and nutrient uptake by macroalgae (see Hurd 2000 for review). Different light compensation points among macroalgae were suggested to influence patterns of vertical distribution of algae and were generally associated with a decreasing complexity in algal structure (canopy, foliose, encrusting) with depth (Markager \& Sand-Jensen 1992).

In addition, the amount of light can affect the dominance of algae and invertebrates. Experimental work has shown that sessile invertebrates generally dominate shaded conditions, whereas macroalgae and mobile invertebrates dominate well lit areas (e.g. Glasby 1999; Blockley \& Chapman 2006). Thus, it is predicted that macroalgae will dominate shallow-water levels, whereas sessile invertebrates will increase in abundance with increasing depth. In addition, by affecting organism fitness and dominance (e.g. Lin \& Carpenter 1997; Muller \& Woesik 2009) light intensity can have indirect community-level cascading effects (e.g. Whitcraft \& Levin 2007). Thus, there is a vertical gradient in the physical environment that influences the distribution of coastal benthic assemblages (Kautsky \& Kautsky 1989; Underwood et al. 1991; Garrabou et al. 2002; Tuya et al. 2007).

However, environmental conditions, such as wave action or depth, cannot fully explain patterns of distribution in marine ecosystems on their own (e.g. Terlizzi et al. 2007) and different processes often interact in structuring biological communities (Benedetti-Cecchi et al. 2000; McQuaid et al. 2000; Saunders \& Connell 2001; Ortega-Borges et al. 2009). Here we investigate the spatial distribution of subtidal benthic assemblages of macroalgae and invertebrates by comparing the assemblage structure on six locations distributed along the north and south coasts of São Miguel island. Furthermore, in each location, sampling was done at shallow and deep water levels so that the potential interactive effects of coast and depth can be examined.

\section{Materials and methods}

\section{Study sites and community}

The study was carried out on subtidal rocky basaltic substrata, where coastal benthic communities in the Azores are dominated by macroalgae. Shallow waters $(\sim 5 \mathrm{~m})$ are dominated by encrusting coralline algae, articulated corallines, Dictyota spp. and Halopteris spp. whereas at deeper levels $(\sim 30 \mathrm{~m})$, communities are domi- nated by Zonaria tournefortii and encrusting coralline algae (Wallenstein et al. 2008a,b). At intermediate depths (10-20 m), communities are a mixture of both shallow and deeper water communities (Wallenstein et al. 2008a, b). Invertebrates, although common, rarely occur at high densities. Conspicuous species include sea-urchins (e.g. Arbacia lixula and Sphaerechinus granularis), star-fish (e.g. Marthasterias glacialis, Ophidiaster ophidianus), sessile polychaetes (e.g. Sabella spallanzani), mobile polychaetes (Hermodice carunculata), decapods (e.g. Calcinus tubularis, Percnon gibbesi) and gastropods (e.g. Stramonita haemastoma, Charonia lampas) (Martins et al. 2005).

São Miguel is a relatively long (west-east) but narrow (north-south) island (see Fig. 1A). The entire coast around São Miguel is exposed to oceanic swell and surge, with the few sheltered locations generally restricted to areas within harbours. However, the frequency of winds on the northern coast (windward) is at least twice that on the southern coast (leeward) (Fig. 1). In addition, according to the Global Atlas of Ocean Waves (http:// www.sail.msk.ru/atlas/index.htm), oceanic swell and significant wave height is generally greater in areas north of the Azores. Around the Azores, swell direction is predominantly from N/NW, suggesting that locations on the south coast are protected by the landmass experiencing a reduced level of exposure to oceanic swells. The Azores are located in the northern region of the North Atlantic Subtropical Gyre and are influenced by the cold southern branch of the North Atlantic Current to the north and the warm Azores Current to the south (Morton et al. 1998; Bashmachnikov et al. 2004). However, an understanding of the interactions between these oceanic currents and coastal morphology around the Azorean islands is still in its infancy and it is difficult to predict whether these factors result in consistent differences that vary with coastal orientation.

Variation in fetch among sampled locations (Fig. 1B, estimated using the model described by Burrows et al. 2008), which is also known to affect the degree of exposure to wave-action (e.g. Burrows et al. 2008), did not differ between the lee and windward coasts ( $t$-test, $\mathrm{P}>0.05$, Fig. 1B).

Water clarity, as measured by Secchi disk, varies seasonally, ranging between 11 and $27 \mathrm{~m}$ with a mean $15.8 \mathrm{~m}$ ( $\mathrm{SE}=0.5 \mathrm{~m}, \mathrm{n}=48$ ) (Neto A.I., Brotas V., Azevedo J.M.N., Patarra R.F., Álvaro N.M.V., Gameiro C., Prestes A.C.L., Nogueira E.M. unpublished data).

\section{Sampling design}

Three locations were respectively selected both on the north and south coasts of São Miguel (Fig. 1A). All locations were similar in terms of substratum and were 
Fig. 1. (A) Map of São Miguel island (Azores) and sampling locations: N1 - Santo Antonio, N2 - Fenais da Luz, N3 - Rabo de Peixe, S1 - Lagoa, S2 - Água d'Alto, S3 Ponta Garça, and (B) wind frequency (continuous line) and intensity (dashed line) based on data from 1961-1990 (Instituto Metereológico) (on the left) and fetch for each location based on the model of Burrows et al. (2008) (on the right).
A

NE Atlantic
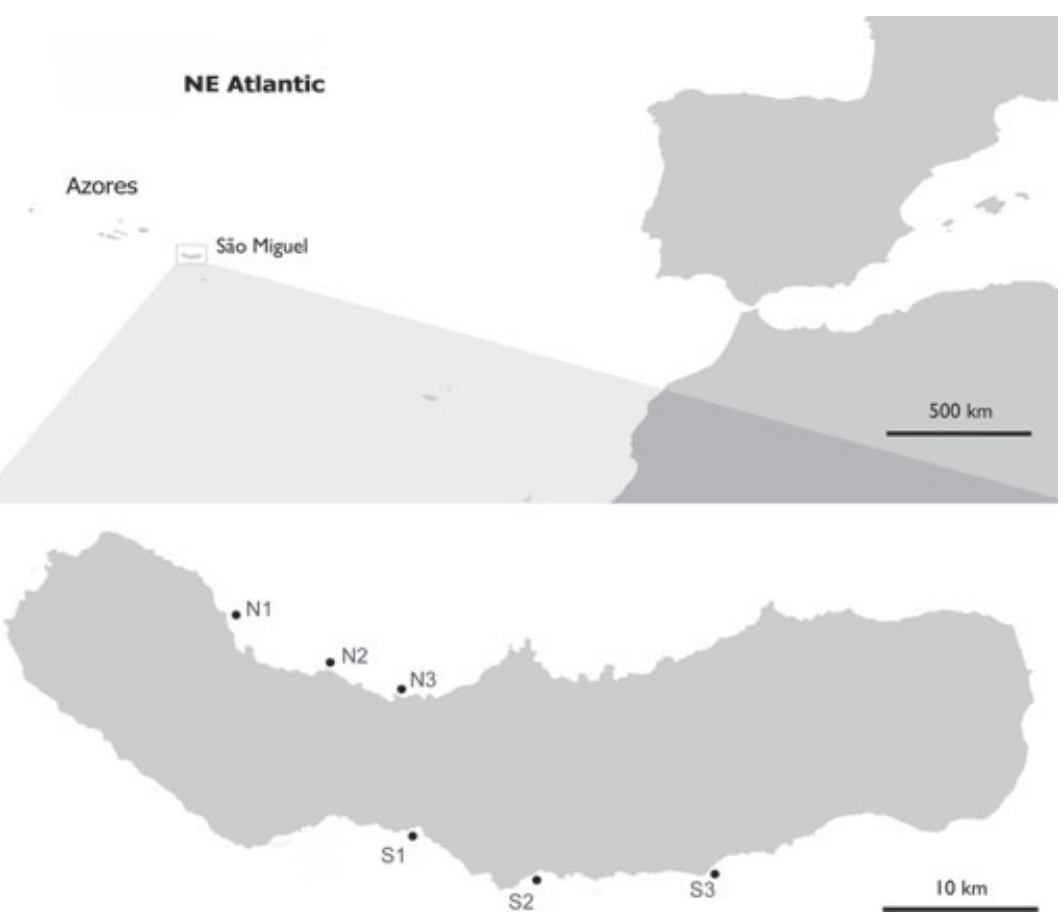

B
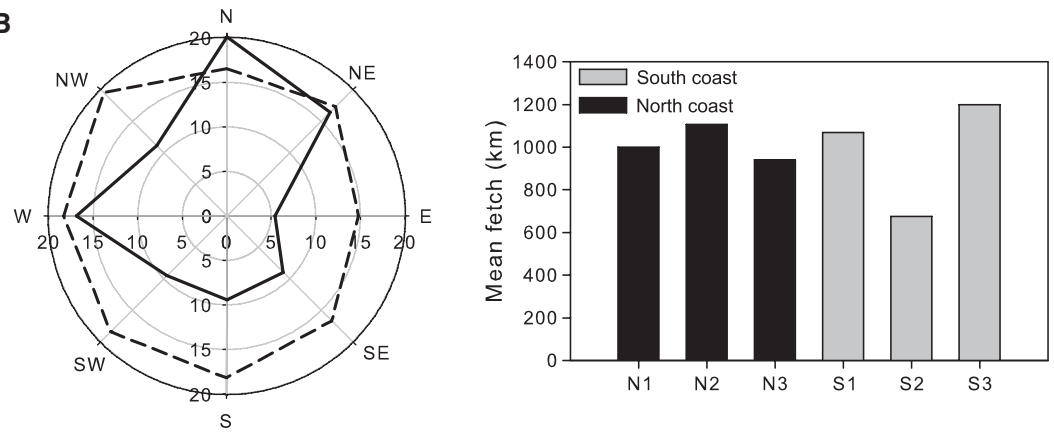

composed of basalt sensu latum with a relative high topographic complexity (convoluted reefs). Sampling was done within areas of gentle sloping substrata $\left(<45^{\circ}\right)$ and avoided large substratum irregularities. At each location, sampling was done at 5 and $25 \mathrm{~m}$ depth. Maximum depth was set considering the time necessary for sampling within safety conditions.

At each location and depth, assemblages of animals and plants were identified in situ by SCUBA diving. The cover of macroalgae was estimated non-destructively in nine $50 \times 50 \mathrm{~cm}$ quadrats $\left(0.25 \mathrm{~m}^{2}\right)$ following the pointintersection method with a grid of 36 points per quadrat. Quadrats were randomly laid in horizontal substrata at least a few meters apart. Algae were identified to the lowest possible taxonomic resolution in the field. Unidentified algae were classified into morphological groups (e.g. filamentous red algae). Final values for each taxon were expressed as percentages.
The abundance of macroinvertebrates was estimated non-destructively in three $15 \times 1 \mathrm{~m}$ transects $\left(15 \mathrm{~m}^{2}\right)$. Transects were visually inspected and all conspicuous $(>2$ $-3 \mathrm{~cm}$ ) invertebrates were counted. The abundance of sessile colonial animals (e.g. sponges) was estimated as the number of colonies. Final values for each taxon were expressed as density (per $15 \mathrm{~m}^{2}$ ). Sampling of macroalgae and invertebrates was done separately using quadrats and transects respectively because these have been shown previously to adequately represent these assemblages (Neto 1997; Martins et al. 2005).

\section{Data analysis}

Hypotheses were tested using univariate and multivariate procedures. For the former, macroalgae were grouped into four morpho-functional groups according to the literature (e.g. Steneck \& Dethier 1994; Fowler-Walker \& 
Table 1. Three-way mixed model ANOVA testing for the effects of coastal orientation ( $n=$ north; $S=$ south), depth (De) and location (Lo) on the abundance of macroalgae.

\begin{tabular}{|c|c|c|c|c|c|c|c|c|c|}
\hline \multirow[b]{2}{*}{ Source } & \multirow[b]{2}{*}{$d f$} & \multicolumn{2}{|l|}{ Turf } & \multicolumn{2}{|l|}{ Bush-like } & \multicolumn{2}{|l|}{ Art. corall. } & \multicolumn{2}{|l|}{ Encrusting } \\
\hline & & $\mathrm{F}$ & $P$ & $\mathrm{~F}$ & $P$ & $\mathrm{~F}$ & $P$ & $\mathrm{~F}$ & $P$ \\
\hline Depth $=$ De & 1 & 13.45 & $*$ & 1.75 & n.s. & 2.67 & n.s. & 0.90 & n.s. \\
\hline Coast $=$ Co & 1 & 9.23 & $*$ & 0.92 & n.s. & 0.06 & n.s. & 1.60 & n.s. \\
\hline Location $(\mathrm{Co})=\mathrm{Lo}(\mathrm{Co})$ & 4 & 8.24 & $* * *$ & 38.14 & $* * *$ & 16.84 & $* * *$ & 51.85 & $* * *$ \\
\hline $\mathrm{De} \times \mathrm{Co}$ & 1 & 4.41 & $*$ & 0.00 & n.s. & 4.14 & n.s. & 0.79 & n.s. \\
\hline $\mathrm{De} \times \mathrm{Lo}(\mathrm{Co})$ & 4 & 1.07 & n.s. ${ }^{\dagger}$ & 10.47 & $* * *$ & 6.16 & $* * *$ & 84.32 & $* * *$ \\
\hline Residual & 96 & & & & & & & & \\
\hline Transformation & & none & & none & & none & & none & \\
\hline Cochran's & & $C=0.32$ & $* *$ & $C=0.32$ & $* *$ & $C=0.34$ & $* *$ & $C=0.29$ & $* *$ \\
\hline \multirow[t]{5}{*}{ SNK } & & Turf & & & & & & & \\
\hline & & $\mathrm{N}: 5 \mathrm{~m}=25 \mathrm{~m}$ & & & & & & & \\
\hline & & $\mathrm{S}: 5 \mathrm{~m}>25 \mathrm{~m}$ & & & & & & & \\
\hline & & $5 \mathrm{~m}: \mathrm{N}<\mathrm{S}$ & & & & & & & \\
\hline & & $25 \mathrm{~m}: \mathrm{N}<\mathrm{S}$ & & & & & & & \\
\hline
\end{tabular}

†Pooled term ( $P>0.25$, Underwood 1997).

${ }^{*} \mathrm{P}<0.05$

${ }^{* *} \mathrm{P}<0.01$

${ }^{* * *} \mathrm{P}<0.001$
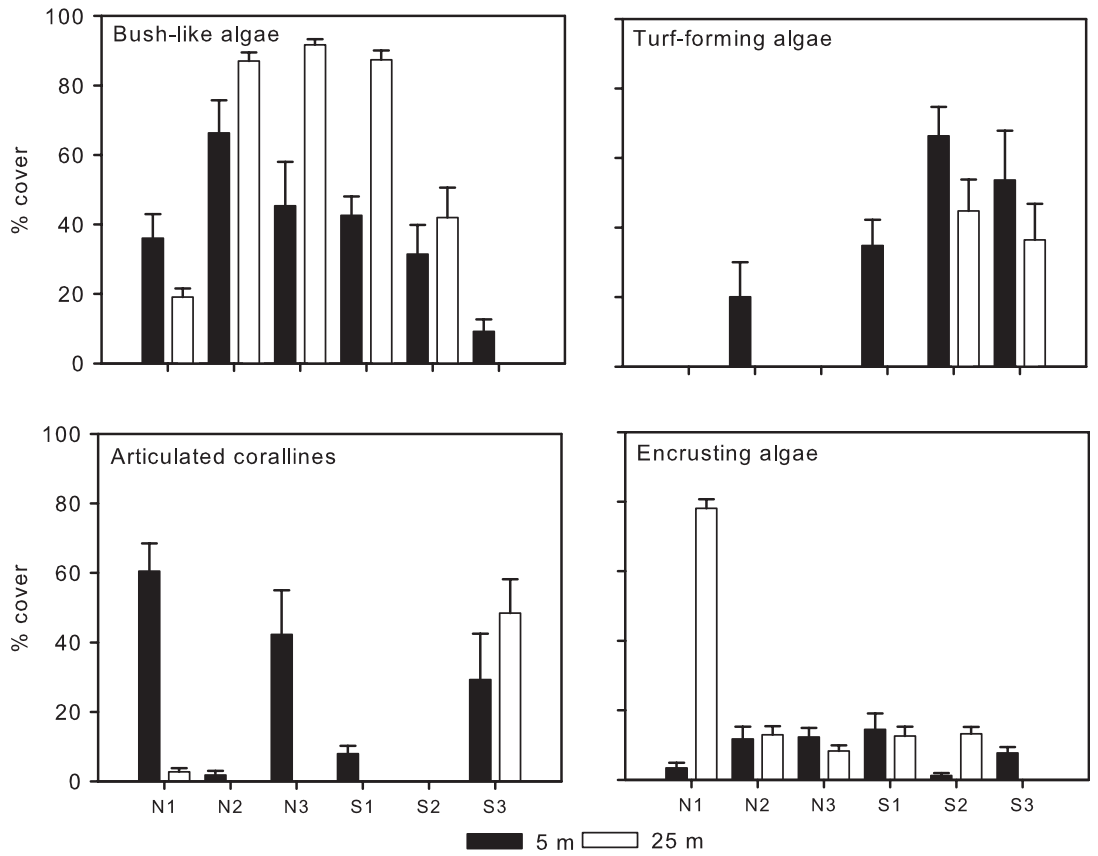

Fig. 2. Mean $(+S E, n=9)$ abundance of macroalgae in relation to coastal orientation and depth. In the $x$-axis, $\mathrm{N}$ or $\mathrm{S}$ indicates north or south coasts, respectively, whereas the numbers stand for each location.

Connell 2002), especially macroalgae from similar habitats within Macaronesia (Tuya \& Haroun 2006). Thus, macroalgae were classified as: turf-forming algae consisting of small cushion-shaped and filamentous algae, generally $<5 \mathrm{~cm}$ height (e.g. Codium spp., Colpomenia sinuosa, Polysiphonia spp.), bush-like algae consisting of sheet-shaped and thick leathery species with $>5 \mathrm{~cm}$ height (e.g. Asparagopsis spp., Dictyota spp., Halopteris spp., Zonaria tournefortii), articulated coralline algae con- sisting of erect calcareous algae (e.g. Corallina elongata, Jania spp.) and encrusting algae (e.g. calcareous and non-calcareous encrusting algae). Invertebrates were also grouped into large morpho-functional groups such as sea-urchins, star-fish, sessile polychaetes and decapods. Because the hypothesis considers patterns of dominant species, univariate analyses of taxa occurring in $<10 \%$ (e.g. corticated and canopy-forming algae such as Sargassum spp.) of the samples were not analysed. For 
multivariate analysis, taxa were examined individually (not grouped).

A three-way mixed model analysis of variance (ANOVA) was used with coast (two levels, fixed), depth (two levels, fixed and orthogonal to orientation) and location (three levels, random and nested within north versus south). Prior to analysis, data were checked for heteroscedasticity (Cochran's test) and transformations were done where appropriate (Underwood 1997). In some situations, heteroscedasticity persisted after transformations. For these, analyses were performed on untransformed data, as ANOVA is relatively robust to departures from this assumption where replication is high (Underwood 1997). Post-comparisons within significant terms were analysed using the StudentNewman-Keuls (SNK) test.

The response of the assemblage as a whole was examined using multivariate procedures with the same three-way mixed model as described for the ANOVA. Analyses were done using permutational multivariate analysis of variance (PERMANOVA, Anderson 2001) and ordination techniques (non-metric multidimensional scaling, Clarke \& Warwick 1994), based on the square root-transformed data and Bray-Curtis dissimilarities.

\section{Results}

\section{Univariate analysis}

For the macroalgae, a significant interaction between coastal orientation and depth was only found for the turf-forming algae (Table 1). SNK analyses showed that the abundance of turf-forming algae was greater in the leeward coast, where it was more abundant at shallow depths. However, in the windward coast its abundance did not vary with depth (Fig. 2, Table 1). For the remaining algal groups (bush-like, articulated and encrusting algae), there was no difference in abundance

Table 2. Three-way mixed model ANOVA testing for the effects of coastal orientation ( $N=$ north; $S=$ south), depth (De) and location (Lo) on the abundance of invertebrates.

\begin{tabular}{|c|c|c|c|c|c|c|c|c|c|c|c|}
\hline \multirow[b]{2}{*}{ Source } & \multirow[b]{2}{*}{$d f$} & \multicolumn{2}{|l|}{ Ascideans } & \multicolumn{2}{|l|}{ Decapods } & \multicolumn{2}{|c|}{ Gastropods } & \multicolumn{2}{|c|}{ Holothurians } & \multicolumn{2}{|c|}{ Mob. Polych. } \\
\hline & & $\mathrm{F}$ & $\mathrm{P}$ & $\mathrm{F}$ & P & $\mathrm{F}$ & P & $\mathrm{F}$ & $P$ & $\mathrm{~F}$ & $P$ \\
\hline De & 1 & 0.20 & n.s. & 0.76 & n.s. & 0.44 & n.s. & 3.38 & n.s. & 35.59 & $* *$ \\
\hline Co & 1 & 11.86 & $*$ & 1.39 & n.s. & 0.44 & n.s. & 0.01 & n.s. & 12.81 & $*$ \\
\hline Lo(Co) & 4 & 0.84 & n.s. & 14.91 & $* * *$ & 10.88 & $* * *$ & 5.16 & $* *$ & 1.80 & n.s. \\
\hline $\mathrm{De} \times \mathrm{Co}$ & 1 & 0.20 & n.s. & 0.65 & n.s. & 1.56 & n.s. & 2.95 & n.s. & 12.81 & $*$ \\
\hline $\mathrm{De} \times \mathrm{Lo}(\mathrm{Co})$ & 4 & 3.09 & $*$ & 5.28 & $* *$ & 10.88 & $* * *$ & 3.43 & $*$ & 1.80 & n.s. \\
\hline Residual & 24 & & & & & & & & & & \\
\hline Transformation & & $x^{0.1}$ & & $\arcsin$ & & none & & $x^{0.1}$ & & none & \\
\hline $\begin{array}{l}\text { Cochran's } \\
\text { SNK }\end{array}$ & & $C=0.25$ & n.s. & $C=0.36$ & n.s. & $C=0.76$ & $* *$ & $C=0.29$ & n.s. & $\begin{array}{c}C=0.31 \\
\text { Mob. Pol } \\
\text { N: } 5 \mathrm{~m}= \\
\text { S: } 5 \mathrm{~m} \\
5 \mathrm{~m}: \\
25 \mathrm{~m}:\end{array}$ & $\begin{array}{l}\text { n.s. } \\
5 \mathrm{~m} \\
5 \mathrm{~m} \\
\mathrm{~s} \\
\mathrm{~s}\end{array}$ \\
\hline
\end{tabular}

\begin{tabular}{|c|c|c|c|c|c|c|c|c|c|}
\hline \multirow[b]{2}{*}{ Source } & \multirow[b]{2}{*}{ df } & \multicolumn{2}{|l|}{ Porifera } & \multicolumn{2}{|l|}{ Sess. Polych. } & \multicolumn{2}{|l|}{ Starfish } & \multicolumn{2}{|l|}{ Urchins } \\
\hline & & $\mathrm{F}$ & $P$ & $\mathrm{~F}$ & $P$ & $\mathrm{~F}$ & $P$ & $\mathrm{~F}$ & $P$ \\
\hline De & 1 & 0.91 & n.s. & 2.29 & n.s. & 2.56 & n.s. & 0.65 & n.s. \\
\hline Co & 1 & 0.05 & n.s. & 0.16 & n.s. & 0.30 & n.s. & 1.02 & n.s. \\
\hline $\mathrm{Lo}(\mathrm{Co})$ & 4 & 10.11 & $* * *$ & 8.34 & $* * *$ & 7.44 & $* * *$ & 7.27 & $* * *$ \\
\hline $\mathrm{De} \times \mathrm{Co}$ & 1 & 0.38 & n.s. & 1.42 & n.s. & 0.16 & n.s. & 1.00 & n.s. \\
\hline $\mathrm{De} \times \mathrm{Lo}(\mathrm{Co})$ & 4 & 7.07 & $* * *$ & 10.49 & $* * *$ & 1.56 & n.s. & 10.15 & $* * *$ \\
\hline Residual & 24 & & & & & & & & \\
\hline Transformation & & $\arcsin$ & & $\sqrt{(x+1)}$ & & none & & $\sqrt{(x+1)}$ & \\
\hline Cochran's & & $C=0.37$ & n.s. & $C=0.35$ & n.s. & $C=0.25$ & n.s. & $C=0.29$ & n.s. \\
\hline
\end{tabular}

${ }^{*} \mathrm{P}<0.05$

${ }^{* *} \mathrm{P}<0.01$

${ }^{* * *} \mathrm{P}<0.001$ 

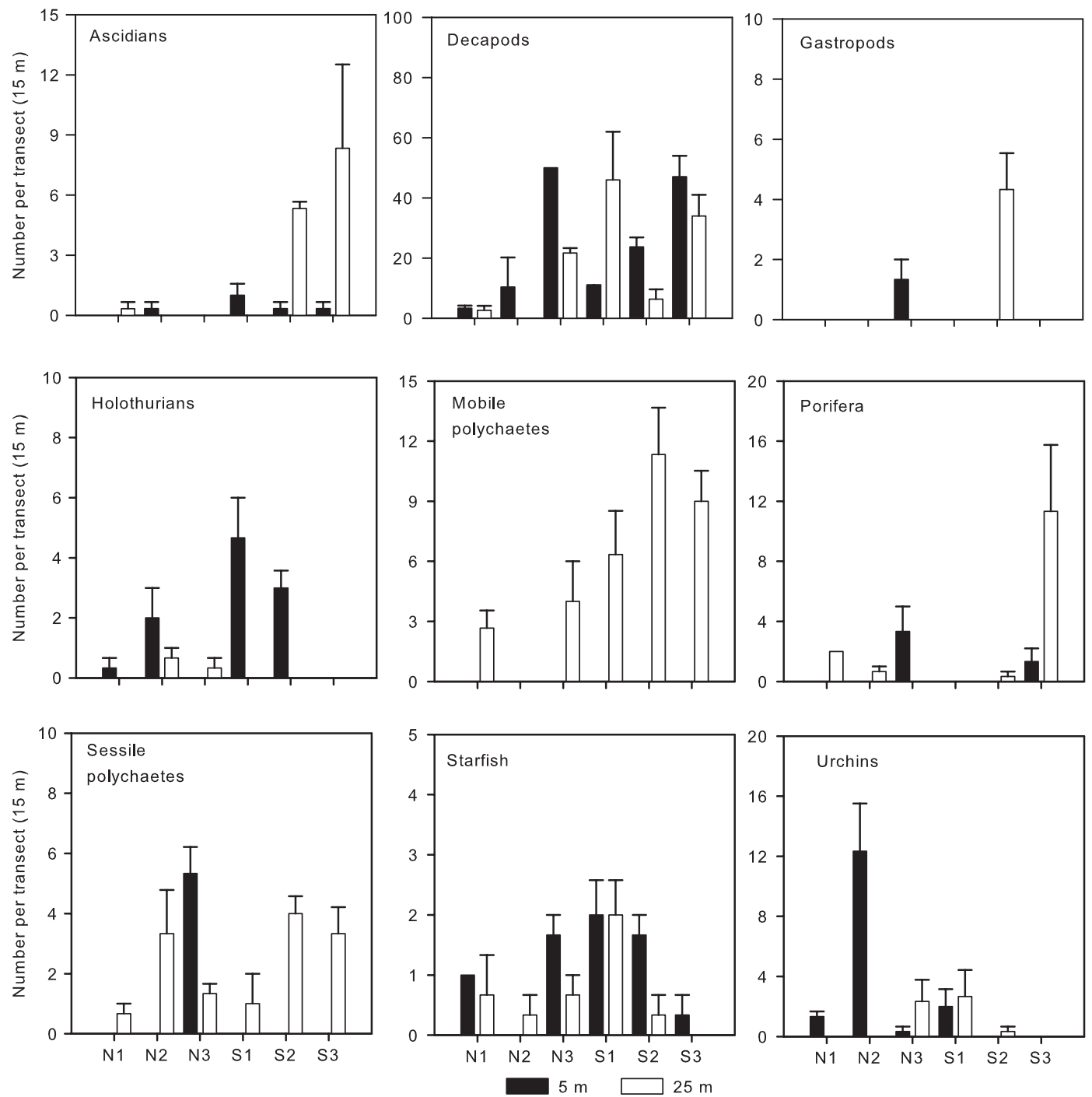

Fig. 3. Mean $(+S E, n=9)$ abundance of invertebrates in relation to coastal orientation and depth. Legend as in Fig. 2. Note the different scales of the $y$ axes.

between the lee and windward coasts (Fig. 2, Table 1) but there were generally differences in abundance between depths, although these were highly variable among locations (Table 1).

For the invertebrates, a significant interaction between depth and coastal orientation was only found for mobile polychaetes (Table 2). SNK tests showed that the abundance of mobile polychaetes was similar in the lee and windward coasts at shallow waters but greater on the leeward coast of the island at deeper water levels (Fig. 3, Table 2). Ascidia responded consistently to coastal orientation, being significantly more abundant on the leeward coast at shallow and deep levels. For the remaining and large majority of the taxa examined, there were no differences in their numbers in relation to coastal orientation but there were generally differences between depths, although patterns were, again, not consistent among locations (Fig. 3, Table 2).

\section{Multivariate analysis}

For macroalgae, differences in multivariate assemblage structure between island coasts were consistent between depths (De $\times$ Co, $\mathrm{P}>0.05$ ), although variability from location to location affected differences between depths [De $\times$ Lo (Co), P < 0.001] (Fig. 4, Table 3). Inspection of pair-wise comparisons showed that despite variability among locations, there were consistent differences in the structure of assemblages at shallow and deeper levels.

Patterns of assemblage structure for invertebrates were similar to that of macroalgae (Fig. 4, Table 3). Hence, the effects of coastal orientation were consistent 

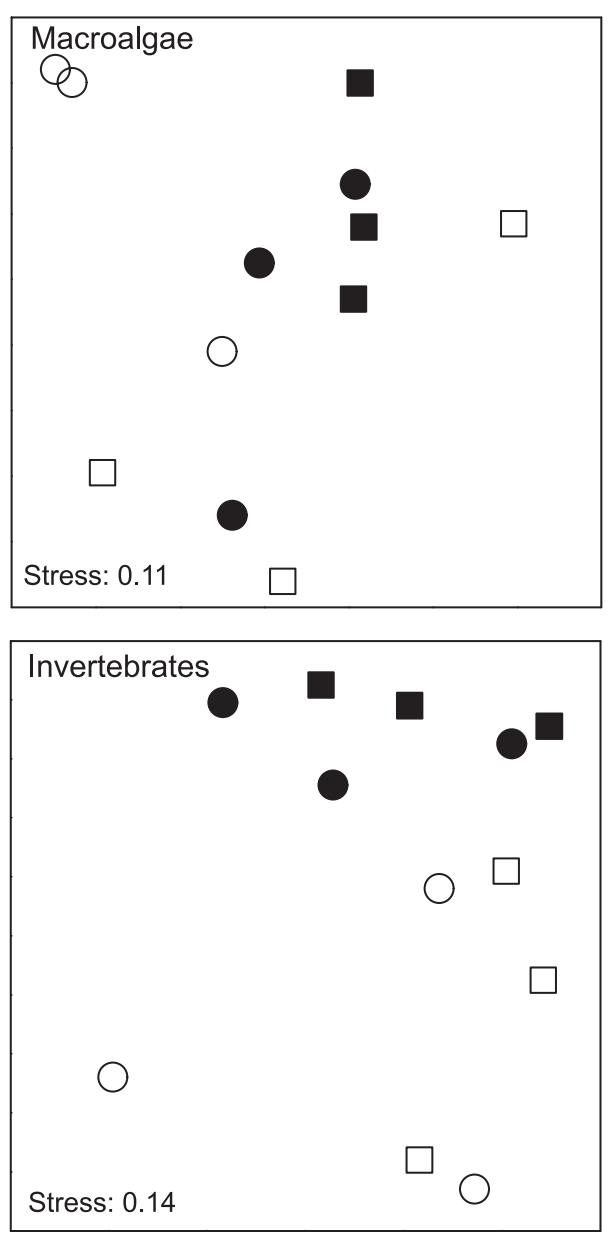

Fig. 4. Non-metrical multidimensional scaling (MDS) representing the assemblage structure of macroalgae (upper plot) and invertebrates (lower plot) according to coastal orientation and depth. For clarity, only the centroids for each location are shown. Open symbols, $25 \mathrm{~m}$; filled symbols, $5 \mathrm{~m}$; squares, southern locations; circles, northern locations.

among depths (De $\times$ Co, $\mathrm{P}>0.05)$, but there was significant spatial variation among depths (De $\times$ Lo $(\mathrm{Co})$, $\mathrm{P}<0.001$ ) with an overall effect of depth (pair-wise comparisons) affecting the structure of assemblages of invertebrates.

\section{Discussion}

Contrary to our predictions of variability associated with coastal orientation, there was generally no interactive effect between coastal orientation and depth. Moreover, most taxa did not respond to differences in coastal orientation at all. In contrast, taxa did generally respond to differences in depth, although patterns were spatially inconsistent. These results indicate that processes operating at the scale of the coast do not play a prominent
Table 3. Three-way mixed model multivariate PERMANOVA testing for the effects of coastal orientation ( $N=$ north; $S=$ south), depth (De) and locations (Lo) over the structure of macroalgal and invertebrate assemblages. Analyses were done on the square-root transformed data and using Bray-Curtis dissimilarity.

\begin{tabular}{|c|c|c|c|c|c|c|c|}
\hline \multirow[b]{2}{*}{ Source } & \multirow[b]{2}{*}{ df } & \multicolumn{2}{|c|}{ Macroalgae } & \multirow[b]{2}{*}{$d f$} & \multicolumn{2}{|c|}{ Invertebrates } & \multirow[b]{2}{*}{ F-ratio } \\
\hline & & $F$ & $P$ & & $F$ & $P$ & \\
\hline De & 1 & 2.75 & n.s. & 1 & 2.63 & n.s. & $\begin{array}{c}\text { De } \times \text { Lo } \\
(\mathrm{N} \text { vs. S })\end{array}$ \\
\hline Co & 1 & 1.54 & n.s. & 1 & 1.13 & n.s. & Lo(N vs. S) \\
\hline Lo(Co) & 4 & 29.91 & $* * *$ & 4 & 10.69 & $* * *$ & Residual \\
\hline $\mathrm{De} \times \mathrm{Co}$ & 1 & 1.44 & n.s. & 1 & 0.64 & n.s. & $\begin{array}{c}\text { De } \times \text { Lo } \\
(\mathrm{N} \text { vs. S })\end{array}$ \\
\hline $\mathrm{De} \times \mathrm{Lo}(\mathrm{Co})$ & 4 & 20.33 & $* * *$ & 4 & 8.72 & $* * *$ & Residual \\
\hline Residual & 96 & & & 24 & & & \\
\hline
\end{tabular}

${ }^{* * *} \mathrm{P}<0.001$

influence on these assemblages. This refutes the anecdotal perception that the northern coast is relatively more exposed to rough sea conditions (well known structuring processes of benthic assemblage; e.g. Lubchenco \& Menge 1978; Blockley \& Chapman 2006). Such general absence of differences in the distribution of organisms between different coasts of islands is also in contrast to the work done in other insular regions (Menge et al. 1999, 2003; Tuya \& Haroun 2006). Unlike the Canary Islands, which are influenced by the trade winds, the Azores are located in the transition between the temperate and sub-tropical regions and experience very unstable meteorological conditions. Although winds in São Miguel blow predominantly from the north, it is clear that wind intensity is similar from all directions (see Fig. 1). This may mean that benthic communities in the south are already exposed to high levels of wave action so that the greater frequency of rough seas found in the north is not relevant. These results also suggest that variable patterns of oceanographic conditions (e.g. eddies, upwelling) such as the ones described for other regions (e.g. Menge et al. 1999, 2003) do not exist at the scale of the coast.

As expected, and unlike coastal orientation, there were generally differences in the structure of benthic assemblages associated with depth, as had been previously described for the region (Wallenstein et al. 2008a,b). However, in 10 of the 13 taxa examined, such differences were highly variable among locations. Variation at this spatial scale is common and has been found in previous studies both intertidally in the Azores (Martins et al. 2008) and elsewhere (e.g. Underwood \& Chapman 1996; Fraschetti et al. 2005). It indicates that processes operating at the scale of the location (kilometers) are important and interact with depth in structuring these assemblages. This was also noted by Terlizzi et al. (2007) in the Medi- 
terranean; they found that, although there were generally characteristic differences in community structure among different depths, there was also high variability at all the spatial (and temporal) scales examined.

The results highlight that an understanding of the relevant scales of variation is key if we are to design experiments that realistically capture the spatial (and temporal) variation in community structure. Here, in spite of depth, processes operating at the scale of the locations, but not at the scale of the coast, play an important role in structuring subtidal benthic communities. Potentially important differences among locations include the fetch, which determines the degree of protection from coastal wave action (see Fig. 1B). Winds and currents are also deformed by terrestrial masses and the topography of the ocean floor generating small-scale complex patterns in near-shore hydrographic conditions (e.g. Hernández-León 1988; Narváez et al. 2004), which can influence the settlement and recruitment of key marine organisms among locations (e.g. Lagos et al. 2005, 2008).

An understanding of the scales at which variation in community structure occurs is a key step before explanatory models for these patterns can be made (Underwood \& Chapman 1996; Hewitt et al. 2007). Further progress in the study of these communities may be hampered by neglecting the intrinsic and pervasive variability in community structure found at the scale of locations.

\section{Acknowledgements}

We thank Fernando Tuya for kindly providing comments on an earlier draft of this manuscript. G.M.M. was supported by a post-doctoral grant (SFRH/BDP/63040/2009) from FCT, Portugal. The surveys performed in the present study comply with the current laws of Portugal. The manuscript greatly benefited from the criticism of two anonymous reviewers.

\section{References}

Anderson M.J. (2001) A new method for non-parametric multivariate analysis of variance. Austral Ecology, 26, 32-46.

Bashmachnikov I., Lafon V., Martins A. (2004) Sea surface temperature distribution in the Azores region: Part II: space-time variability and underlying mechanisms. Arquipélago - Life and Marine Sciences, 21A, 19-32.

Benedetti-Cecchi L., Bulleri F., Cinelli F. (2000) The interplay of physical and biological factors in maintaining mid-shore and low-shore assemblages on rocky coasts in the northwest Mediterranean. Oecologia, 123, 406-417.

Blanchette C.A. (1997) Size and survival of intertidal plants in response to wave action: a case study with Fucus gardneri. Ecology, 78, 1563-1578.
Blockley D.J., Chapman M.G. (2006) Recruitment determines differences between assemblages on shaded or unshaded seawalls. Marine Ecology Progress Series, 327, 27-36.

Burrows M.T., Harvey R., Robb L. (2008) Wave exposure indices from digital coastlines and the prediction of rocky shore community structure. Marine Ecology Progress Series, $353,1-12$.

Clarke K.R., Warwick R.M. (1994) Change in marine communities: an approach to statistical analysis and interpretation. Natural Environment Research Council, Plymouth.

Denny M.W.. (1988) Biology and mechanics of the wave-swept environment. PhD Thesis, Princeton University, Princeton.

Fowler-Walker M.J., Connell S.D. (2002) Opposing states of subtidal habitat across temperate Australia: consistency and predictability in kelp canopy-benthic associations. Marine Ecology Progress Series, 240, 49-56.

Fraschetti S., Terlizzi A., Benedetti-Cecchi L. (2005) Patterns of distribution of rocky marine assemblages: evidence of relevant scales of variation. Marine Ecology Progress Series, 296, 13-29.

Garrabou J., Ballesteros E., Zabala M. (2002) Structure and dynamics of north-western Mediterranean rocky benthic communities along a depth gradient. Estuarine, Coastal and Shelf Science, 55, 493-508.

Glasby T.M. (1999) Interactive effects of shading and proximity to the seafloor on the development of subtidal epibiotic assemblages. Marine Ecology Progress Series, 190, 113-124.

Hassett R.P., Boehlert G.W. (1999) Spatial and temporal distributions of copepods to leeward and windward of Oahu, Hawaiian Archipelago. Marine Biology, 134, 571-584.

Hernández-León S. (1988) Gradients of mesozooplankton biomass and ETS activity in the wind-shear area as evidence of an island mass effect in the Canary Island waters. Journal of Plankton Research, 10, 1141-1154.

Hewitt J.E., Thrush S.F., Dayton P.K., Bonsdorff E. (2007) The effect of spatial and temporal heterogeneity on the design and analysis of empirical studies of scale-dependent systems. American Naturalist, 169, 398-408.

Hurd C.L. (2000) Water motion, marine macroalgal physiology, and production. Journal of Phycology, 36, 453-472.

Jonsson P.R., Granhag L., Moschella P.S., Åberg P., Hawkins S.J., Thompson R.C. (2006) Interactions between wave action and grazing control the distribution of intertidal macroalgae. Ecology, 87, 1169-1178.

Kautsky L., Kautsky H. (1989) Algal species diversity and dominance along gradients of stress and disturbance in marine environments. Vegetatio, 83, 259-267.

Lagos N.A., Navarrete S.A., Véliz F., Masuero A., Castilla J.C. (2005) Meso-scale spatial variation in settlement and recruitment of intertidal barnacles along the coast of central Chile. Marine Ecology Progress Series, 290, 165-178.

Lagos N.A., Castilla J.C., Broitman B.B. (2008) Spatial environmental correlates of intertidal recruitment: a test using barnacles in northern Chile. Ecological Monographs, 78, 245-261. 
Lin S., Carpenter E.J. (1997) Rubisco of Dunaliella tertiolecta is redistributed between the pyrenoid and the stroma as a light/shade response. Marine Biology, 127, 521-529.

Lubchenco J., Menge B.A. (1978) Development and persistence in a low rocky intertidal zone. Ecological Monographs, 48, 67-94.

Markager S., Sand-Jensen K. (1992) Light requirements and depth zonation of marine macroalgae. Marine Ecology Progress Series, 88, 83-92.

Martins G.M., Wallenstein F.F.M.M., Álvaro N.V., Neto A.I., Costa A.C. (2005) Sampling strategies for biotope definition: minimal sampling area for selected groups of macroinvertebrates in the rocky subtidal of São Miguel, Azores. Helgoland Marine Research, 59, 219-223.

Martins G.M., Thompson R.C., Hawkins S.J., Neto A.I., Jenkins S.R. (2008) Rocky intertidal community structure in oceanic islands: scales of spatial variability. Marine Ecology Progress Series, 356, 15-24.

McQuaid C.D., Lindsay T.L. (2007) Wave exposure effects on population structure and recruitment in the mussel Perna perna suggest regulation primarily through availability of recruits and food, not space. Marine Biology, 151, 2123-2131.

McQuaid C.D., Lindsay J.R., Lindsay T.L. (2000) Interactive effects of wave exposure and tidal height on population structure of the mussel Perna perna. Marine Biology, 137, 925-932.

Menconi M., Benedetti-Cecchi L., Cinelli F. (1999) Spatial and temporal variability in the distribution of algae and invertebrates on rocky shores in the northwest Mediterranean. Journal of Experimanl Marine Biology and Ecology, 233, 1-23.

Menge B.A., Daley B.A., Lubchenco J., Sanford E., Dahlhoff E., Halpin P.M., Hudson G., Burnaford J.L. (1999) Top-down and bottom-up regulation of New Zealand rocky interdial communities. Ecological Monographs, 69, 297-330.

Menge B.A., Lubchenco J., Bracken M.E.S., Chan F., Foley M.M., Freldenberg T.L., Gaines S.D., Hudson G., Krenz C., Leslie H., Menge D.N.L., Russell R., Webster M.S. (2003) Coastal oceanography sets the pace of rocky intertidal community dynamics. Proceedings of the National Academy of Sciences of the United States of America, 100, 12229-12234.

Morton B., Britton J.C., Martins A.M.F. (1998) Coastal ecology of the Azores. Sociedade Afonso Chaves, Ponta Delgada: 249.

Muller E.M., Woesik R. (2009) Shading reduces coral-disease progression. Coral Reefs, 28, 757-760.

Narváez D.A., Poulin E., Leiva G., Hernández E., Castilla J.C., Navarrete S.A. (2004) Seasonal and spatial variation of nearshore hydrographic conditions in central Chile. Continental Shelf Research, 24, 279-292.

Neto A.I. (1997) Studies on algal communities of São Miguel, Azores. PhD Thesis University of Azores, Azores.

Ortega-Borges L., Tuya F., Haroun R.J. (2009) Does depth and sedimentation interact with sea urchins to affect algal assemblages patterns on eastern Atlantic reefs? Journal of Shellfish Research, 28, 947-955.
Saunders R.J., Connell S.D. (2001) Interactive effects of shade and surface orientation on the recruitment of spirorbid polychaetes. Austral Ecology, 26, 109-115.

Steneck R.S., Dethier M.N. (1994) A functional group approach to the structure of algal-dominated communities. Oikos, 69, 476-498.

Taylor D.I., Schiel D.R. (2010) Algal populations controlled by fish herbivory across a wave exposure gradient on southern temperate shores. Ecology, 91, 201-211.

Terlizzi A., Anderson M.J., Fraschetti S., Benedetti-Cecchi L. (2007) Scales of spatial variation in Mediterranean subtidal assemblages at different depths. Marine Ecology Progress Series, 332, 25-39.

Tuya F., Haroun R.J. (2006) Spatial patterns and response to wave exposure of shallow water algal assemblages across the Canarian Archipelago: a multi-scaled approach. Marine Ecology Progress Series, 311, 15-28.

Tuya F., Cisneros-Aguirre J., Ortega-Borges L., Haroun R.J. (2007) Bathymetric segregation of sea urchins on reefs of the Canarian Archipelago: role of flow-induced forces. Estuarine, Coastal and Shelf Science, 73, 481-488.

Underwood A.J. (1981) Structure of a rocky inter-tidal community in New South Wales - Patterns of vertical distribution and seasonal changes. Journal of Experimental Marine Biology and Ecology, 51, 57-85.

Underwood A.J. (1997) Experiments in ecology: their logical design and interpretation using analysis of variance. Cambridge University Press, Cambridge.

Underwood A.J., Chapman M.G. (1996) Scales of spatial patterns of distribution of intertidal invertebrates. Oecologia, 107, 212-224.

Underwood A.J., Kingsford M.J., Andrew N.L. (1991) Patterns in shallow subtidal marine assemblages along the coast of New South Wales. Austral Journal of Ecology, 16, 231-249.

Vadas R.L., Wright W.A., Miller S.L. (1990) Recruitment of Ascophyllum nodosum: wave action as a source of mortality. Marine Ecology Progress Series, 61, 263-272.

Vergés A., Alcoverro T., Ballesteros E. (2009) Role of fish herbivory in structuring the vertical distribution of canopy algae Cystoseira spp. in the Mediterranean Sea. Marine Ecology Progress Series, 375, 1-11.

Wallenstein F.M., Neto A.I., Álvaro N.V., Santos C.I. (2008a) Algae-based biotopes of the Azores (Portugal): spatial and seasonal variation. Aquatic Ecology, 42, 547-559.

Wallenstein F.F.M.M., Neto A.I., Álvaro N.V., Titley I. (2008b) Subtidal rocky shore biotopes of the Azores: developing a biotope survey method. Journal of Coastal Research, 24, 244-249.

Wernberg T., Connell S.D. (2008) Physical disturbance and subtidal habitat structure on open rocky coasts: effects of wave exposure, extent and intensity. Journal of Sea Research, 59, 237-248.

Whitcraft C.R., Levin L.A. (2007) Regulation of benthic algal and animal communities by salt marsh plants: impact of shading. Ecology, 88, 904-917. 